\title{
Comparative Assessment of Physical and Chemical Characteristics of Prickly Pear Seed Oil from Opuntia ficus-indica and Opuntia megacantha Varieties
}

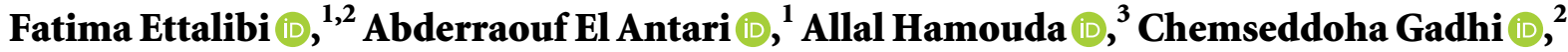 \\ and Hasnaâ Harrak (D) ${ }^{1}$ \\ ${ }^{1}$ Agro-Food Technology and Quality Laboratory, Research Unit of Plant Improvement and Quality, \\ Regional Center of Agricultural Research of Marrakesh, National Institute of Agricultural Research, Avenue Ennasr, \\ P.O. Box 415, Rabat-Principale, Rabat 10090, Morocco \\ ${ }^{2}$ Laboratory of Agri-Food Biotechnology and Valorisation of Plant Resources, \\ Unit of Phytochemistry and Pharmacology of Aromatic and Medicinal Plants, Faculty of Sciences Semlalia, \\ Cadi Ayyad University, P.O. Box 2390, Marrakesh 40000, Morocco \\ ${ }^{3}$ Department of Applied Statistics and Informatics, Hassan II Institute of Agronomy and Veterinary Medecine, P.O. Box 6202, \\ Rabat-Instituts, Rabat 10112, Morocco \\ Correspondence should be addressed to Hasnaâ Harrak; h.harrak@yahoo.fr
}

Received 15 April 2021; Revised 20 July 2021; Accepted 10 September 2021; Published 20 September 2021

Academic Editor: Milan Stankovic

Copyright ( $\odot 2021$ Fatima Ettalibi et al. This is an open access article distributed under the Creative Commons Attribution License, which permits unrestricted use, distribution, and reproduction in any medium, provided the original work is properly cited.

\begin{abstract}
The prickly pear (Opuntia spp.) is an important plant in the economies of arid and semiarid areas, considering its low agronomic requirements and high water use efficiency. Characterizing the chemical composition of this plant will open new avenues for food, pharmaceutical, and cosmetic applications. In this context, this study examined the physical and chemical parameters of fruit seed oils of two prickly pear species from Rhamna area located in the center of Morocco: Opuntia ficus-indica (OFI), represented by the varieties "Safra" and "Aakria," and Opuntia megacantha (OM), represented by the variety "Derbana." The evaluated parameters included oil content, free acidity, specific extinction coefficients $\left(\mathrm{K}_{232}\right.$ and $\left.\mathrm{K}_{270}\right)$, pigment content, fatty acid, and triglyceride composition. The seed oil contents of the three varieties "Safra," "Aakria," and "Derbana" were 8.09\%, 8.74\%, and 8.04\%, respectively. OM ("Derbana") seed oil was the most stable. The three studied varieties had higher contents of $\alpha$-pheophytin and carotenoids than that of chlorophyll. Oil from the "Aakria" variety was distinguished by having the highest contents of $\alpha$-pheophytin and chlorophyll. Significant differences in some fatty acid and triglyceride contents were noted. The major fatty acids of the three varieties were linoleic acid (60.55\%-63.46\%), followed by oleic acid (18.88\%-21.81\%) and palmitic acid (13.03\%$13.75 \%)$. Furthermore, the chromatographic profiles of the triglycerides have shown the dominance of trilinolein (LLL, 24.33\%26.49\%) and oleoyl-dilinoleoyl-glycerol (OLL, 20.92\%-21.92\%). Some triglycerides could be considered species markers, especially OLL, dipalmitoyl-linoleoyl-glycerol (PPL), oleoyl-linoleoyl-linolenoyl-glycerol and palmitoyl-oleoyl-dilinoleoyl-glycerol fraction (OLLn + PoLL), and stearoyl-dioleoyl-glycerol (SOO). This study provides a basis for qualitatively evaluating the therapeutic and cosmetic potential of prickly pear derivatives and for establishing quality standards of seed oil derived from the two species studied.
\end{abstract}

\section{Introduction}

The prickly pear (Opuntia spp.) belongs to the Cactaceae family. Native to Mexico, it was introduced into the Mediterranean region around the end of the 15th century and into North Africa around the end of the 16th century [1]. Opuntia ficus-indica (OFI) is a spineless and dominant species. It is found in different varieties that differ in color and that are harvested in varying stages of ripeness. Opuntia megacantha $(\mathrm{OM})$ is a thorny species that is mainly used for 
farm fencing. The seeds are used for oil extraction [2]. Phenology studies of these species have shown that they produce vegetative and floral buds during the spring and undergo long periods of fruit development in the summer [3].

Currently, the prickly pear is of great interest not only for its ecological roles but also for its potential in food, industrial, pharmaceutical, and cosmetic applications. The literature reports promising information concerning the biological activities and chemical composition of different parts of this plant (fruit pulp, cladodes, seeds, and flowers). Pulps, peels, and cladodes are rich in bioactive compounds, especially antioxidants, including vitamin $\mathrm{C}$, vitamin E, carotenoids, flavonoids, glutathione, and pigments [4-6].

The seeds constitute $2-3.8 \%$ of the fruit weight [7]. The oil is rich in polyunsaturated fatty acids. Linoleic acid was established as a major fatty acid in seed oils, followed by oleic and palmitic acids. Myristic, stearic, and arachidonic acids were detected in OFI seed oil in low amounts [8-10]. Significant levels of vitamins (tocopherol and vitamin K1) and sterols were also found in this oil. Beta-sitosterol was the sterol marker, accounting for $72 \%$ of the total. The major tocopherol is gamma-tocopherol, representing an average of $90 \%$ of total tocopherols, compared with deltatocopherol (9\%) and alpha-tocopherol (1.8\%) [11]. Furthermore, prickly pear seed oil has a rich aroma because of acids, alcohols, aldehydes, esters, hydrocarbons, ketones, and other compounds, such as 2-propenal, acetic acid, pentanal, 1-pentanol, hexanal, 2-hexenal, heptanal, 2heptenal $(\mathrm{Z})$, octanal, 2-octenal, nonanal, 2,4-decadienal (E,E), and trans-4,5-epoxy-(E)-2-decenal [12]. However, the chemical composition of this oil, particularly its fatty acid and tocopherol composition, changes according to geographic origin [13].

Previous studies have conducted useful chemical investigations to evaluate the therapeutic and cosmetic potential of prickly pear seed oil. However, for other oils sold worldwide, such as olive oil and argan oil, quality standards have been established; such standards for prickly pear seed oil are lacking. Therefore, extensive studies on the purity and quality of prickly pear seed oil and its shelf life are essential to promote the quality and utility of this product on a commercial scale. A recent study focused on the sanitary and commercial quality related to the oxidative stability under different storage conditions and adulteration detection of prickly pear seed oil, especially in OFI species [14].

The present study aims to establish a comparative assessment through the physical and chemical characterizations of prickly pear seed oils of three varieties belonging to two species of the prickly pear (Opuntia spp.): OM species locally called "Derbana" and OFI species represented by the varieties "Safra" and "Aakria" from Rhamna, located in the center of Morocco. To the best of our knowledge, this is the first study to compare seed oils of these prickly pear species. The results of this investigation will also provide useful information for future studies evaluating the therapeutic and cosmetic potential of prickly pear seed oil.

\section{Materials and Methods}

2.1. Plant Material and Oil Extraction. Two prickly pear species (Opuntia spp.) collected from the Rhamna region (central Morocco) were studied.

(i) Two varieties of OFI: (i) the variety with yellow orange pulp locally called "Safra" or "Mles" and (ii) the variety with carmine red pulp, locally called "Aakria."

(ii) OM: locally called "Derbana" or "El-Hercha" [2].

Homrani Bakali et al. [7] reported that two prickly pear types, spineless and spiny, are represented, respectively, by Opuntia ficus-indica f. ficus-indica (OFI) and Opuntia ficusindica f. amyclaea, taxonomic synonym (homotypic) of Opuntia megacantha (OM), and nomenclatural synonym (heterotypic) of Opuntia amyclaea.

The plant voucher specimens of the two species used in this study were deposited at the Regional Herbarium "MARK" of the Faculty of Sciences Semlalia, Cadi Ayyad University (Marrakesh, Morocco).

The fruits of both species, OFI and OM, were harvested at the ripe stage in the Skhour Rhamna region, located approximately $100 \mathrm{~km}$ north of Marrakesh (Rhamna Province, Morocco). They were hand-peeled, and the pulp was separated from the seeds using a hand crusher and sieve. The seeds were then washed thoroughly with water, dried in an oven at $30^{\circ} \mathrm{C}$ for $24 \mathrm{~h}$, and crushed using a PULVERISETTE 14 grinder (Fritsch International, Germany).

First, $45 \mathrm{~g}$ of seed powder was collected for each variety; then, the oils were extracted with hexane using a Soxhlet extraction system for $6 \mathrm{~h}$ at $65^{\circ} \mathrm{C}$. At the end of the extraction, the organic phase was evaporated using a rotary evaporator under vacuum with minimal heating $\left(40^{\circ} \mathrm{C}\right)$. The obtained oil was placed in dark glass vials for protection from light and bubbled with a stream of nitrogen to remove residual traces of hexane. The vials were stored at $4^{\circ} \mathrm{C}$ until further analysis. The oil content is expressed in $\mathrm{g} / 100 \mathrm{~g}$ of seed powder.

\subsection{Determination of Oil Physical Quality Parameters.} The oil-specific extinction coefficients $\mathrm{K}_{232}$ and $\mathrm{K}_{270}$, which are used to evaluate conjugated dienes and conjugated trienes, respectively, were determined according to the IOC standard [15].

For free acidity determination, the method used was described by the standard NF.T 60-204 [16]. Briefly, $1 \mathrm{~g}$ of oil was obtained in $20 \mathrm{~mL}$ of an equal volume of ether/ethanol $(50 / 50, \mathrm{v} / \mathrm{v})$ and neutralized, and then, free fatty acids were titrated using an ethanolic potassium hydroxide solution in the presence of phenolphthalein. The end product exhibited a slightly pink color.

\subsection{Determination of Oil Chemical Parameters}

2.3.1. Pigment Content. The pigment content of prickly pear seed oil (expressed in ppm) was determined according to the methods described by Wolff [17] for chlorophyll, Psomiadou 
and Tsimidou [18] for $\alpha$-pheophytin, and Mosquera-Minguez et al. [19] for carotenoids. The fractions of $\alpha$-pheophytin and chlorophyll were quantified at wavelengths of 630,670 , and $710 \mathrm{~nm}$, and those of the carotenoids were determined at $470 \mathrm{~nm}$.

2.3.2. Fatty Acid Composition. Fatty acid composition was determined by the gas chromatography analysis according to the analytical methods described in the IOC standard [20]. Fatty acid methyl esters (FAMEs) were prepared by adding $0.2 \mathrm{~mL}$ of a methanolic solution of potassium hydroxide $(2 \mathrm{~N})$ to the oil solution prepared with $0.1 \mathrm{~g}$ of oil and $n$ heptane $(2 \mathrm{~mL})$. Before injection into the chromatograph, the $n$-heptane solution was shaken vigorously for $15 \mathrm{~s}$ and allowed to stand until the upper part became clear $(5 \mathrm{~min})$. The fatty acids separation was carried out using gas chromatograph Varian CP 3380, equipped with a capillary column packed with a stationary phase (CP-Wax $50 \mathrm{CB}$ : length $L=25 \mathrm{~m}$; inner diameter $\Phi=0.25 \mathrm{~mm} ; \mathrm{Ft}=0.20 \mu \mathrm{m}$ ), using split/splitless injector (split ratio of $1: 100$ ) equipped with the autosampler Varian CP-8400 and FID detector. The temperatures of the injector, detector, and oven were 220 , 230 , and $190^{\circ} \mathrm{C}$, respectively. Nitrogen was used as the carrier gas at a flow rate of $154.0 \mathrm{~mL} / \mathrm{min}$. The injection volume was $1 \mu \mathrm{L}$. Fatty acids were identified by the use of control fatty acids and by the recourse to the methods of imprinting. For fatty acid quantification, the total area (TA) was the sum of all the peaks that appeared in the chromatogram, from C16: 0 to C20:1. The percentage of each peak (FAx (\%)) was calculated using the following equation:

$$
\operatorname{FAx}(\%)=100\left(\frac{\mathrm{Ax}}{\mathrm{AT}}\right),
$$

where Ax is the individual peak area of each FAME and AT is the total area of all FAME peaks.

Based on fatty acid composition, the iodine value (IV), which measures the level of unsaturation in oils and is expressed in grams of iodine absorbed by $100 \mathrm{~g}$ of oil, was calculated from the percentages of fatty acids (FA) according to the following equation proposed by Drraman and Dibeklioğlu [21]:

$$
\begin{aligned}
\mathrm{IV}= & (\% \text { palmitoleic acid } \times 1.001)+(\% \text { oleic acid } \times 0.899) \\
& +(\% \text { linoleic acid } \times 1.814)+(\% \text { linolenic acid } \times 2.737) .
\end{aligned}
$$

2.3.3. Triglyceride Composition. The triglyceride composition was analyzed by high-performance liquid chromatography (HPLC) (Jasco PU, 2080) with a refractive index detector (RI-930), a type recorder-integrator (FP, 1520), and a stainless steel column $(250 \mathrm{~mm} \times 4.5 \mathrm{~mm}$, LiChrosorb, RP 18 , Art 50333) filled with silica particles of $5 \mu \mathrm{m}$ in diameter. The eluent was a mixture of acetone and acetonitrile (50/50, $\mathrm{v} / \mathrm{v}$ ) at a flow rate of $1.5 \mathrm{ml} / \mathrm{min}$ at $40^{\circ} \mathrm{C}$. A volume of $20 \mu \mathrm{L}$ of $5 \%(\mathrm{w} / \mathrm{v})$ oil and acetone solution was injected into the HPLC system. The triglycerides were identified using the official EEC method [22].
The chemical parameters of the studied oils were compared to those of other fruit and seed oils, especially those of argan seeds (Argania spinosa), sesame seeds (Sesamum indicum), black cumin or Nigella seeds (Nigella sativa), olive fruit (Olea europaea), and lentisk seeds (Pistacia lentiscus). Selection of these oils was based on their characteristics, which are well defined and are widely used in various applications, especially in nutraceuticals and cosmetics.

2.4. Statistical Analyses. Data are presented in tables and figures as the mean \pm standard error of three independent experiments. Statistical analysis was performed using oneway analysis of variance (ANOVA) where the varieties constitute the only factor considered. The comparison between the means was carried out with the Student-Newman-Keuls test. The difference between means was significant at $p<0.05$.

\section{Results and Discussion}

3.1. Oil Content. The respective seed oil contents of OFI ("Safra" and "Aakria") and OM ("Derbana") varieties were $8.09 \%, 8.74 \%$, and $8.04 \%$ (Table 1). The "Aakria" variety had the highest oil content $(8.74 \%)$. These results are in agreement with those obtained for Algerian OFI varieties by Chougui et al. [29] and Ramadan and Mörsel [9]. However, higher oil content (up to 14.4\%) has been reported for a Turkish OFI variety by Matthäus and Özcan [13], who reported that the difference in the oil content of the seeds can be attributed to varietal and environmental effects. The oil content of prickly pear seeds appears to be very low compared to that of other plant species from which oils are derived, including argan seeds (53\%) [25], sesame seeds (52\%) [26], Nigella seeds (37\%) [27], olive fruits $(20 \%-$ $40.73 \%)[23,24]$, and lentisk seeds $(7.67 \%-21.33 \%)$ [28].

3.2. Physical Quality Parameters. Free acidity values varied from $0.60 \%$ to $0.71 \%$ for the oils of the three studied varieties. The one-way ANOVA analysis did not show a significant difference between these varieties, indicating that they exhibited the same level of quality. Indeed, these values also provide information on the quality of prickly pear oil, which is comparable to that of extra virgin olive oil $(<0.8 \%)$. They are even lower than the free acidity values reported for sesame oil (free acidity: 0.92\%) [26] or for Nigella oil (free acidity: $2.30 \%$ ) [27]. Therefore, this confers a higher quality to the prickly pear oil of the Rhamna region than that of the oils of these two latter plants; however, this quality is relatively low compared with that of argan oil (free acidity: $0.28 \%$ ) [25] (Table 1).

Concerning the extinction coefficients, the oil derived from the OM variety ("Derbana") yielded significantly lower K232 and K270values (1.82 and 0.66, respectively) compared to that of the oil of the OFI varieties ("Safra" and "Aakria") (Table 1). Based on the obtained extinction coefficients and comparison with other oils, the oils of the three prickly pear varieties were found to be more stable against oxidation than 
TABLE 1: Oil content and quality parameters of seed oils of two prickly pear species: Opuntia ficus-indica ("Safra" and "Aakria” varieties) and Opuntia megacantha ("Derbana" variety) compared with other nutraceutical and cosmetic oils*.

\begin{tabular}{|c|c|c|c|c|c|c|c|c|}
\hline \multirow{3}{*}{ Parameters } & \multicolumn{3}{|c|}{ Prickly pear species and varieties } & \multicolumn{5}{|c|}{ Nutraceutical and cosmetic fruits or seed oils } \\
\hline & \multicolumn{2}{|c|}{ Opuntia ficus-indica } & \multirow{2}{*}{$\begin{array}{c}\text { Opuntia } \\
\text { megacantha } \\
\text { Derbana }\end{array}$} & \multirow{2}{*}{$\begin{array}{c}\text { Olive, Olea } \\
\text { europaea } \\
{[23,24]}\end{array}$} & \multirow{2}{*}{$\begin{array}{c}\text { Argan, } \\
\text { Argania } \\
\text { spinosa [25] }\end{array}$} & \multirow{2}{*}{$\begin{array}{c}\text { Sesame, } \\
\text { Sesamum } \\
\text { indicum [26] }\end{array}$} & \multirow{2}{*}{$\begin{array}{c}\text { Black cumin, } \\
\text { Nigella sativa } \\
\text { [27] }\end{array}$} & \multirow{2}{*}{$\begin{array}{c}\text { Lentisk, } \\
\text { Pistacia } \\
\text { lentiscus }[28]\end{array}$} \\
\hline & Safra & Aakria & & & & & & \\
\hline Oil content (\%) & $8.09^{\mathrm{a}} \pm 0.06$ & $8.74^{\mathrm{b}} \pm 0.03$ & $8.04^{\mathrm{a}} \pm 0.03$ & $20-40.73$ & 53.00 & 52.00 & 37.00 & $7.67-21.33$ \\
\hline Free acidity $(\%)$ & $0.71^{\mathrm{a}} \pm 0.04$ & $0.64^{\mathrm{a}} \pm 0.04$ & $0.60^{\mathrm{a}} \pm 0.04$ & $<0.80$ & 0.28 & 0.92 & 2.30 & - \\
\hline $\begin{array}{l}\text { Extinction } \\
\text { coefficient } \mathrm{K}_{232}\end{array}$ & $2.25^{\mathrm{b}} \pm 0.03$ & $2.24^{\mathrm{b}} \pm 0.04$ & $1.82^{\mathrm{a}} \pm 0.07$ & $<2.50$ & 1.12 & 1.73 & 2.21 & - \\
\hline $\begin{array}{l}\text { Extinction } \\
\text { coefficient } \mathrm{K}_{270}\end{array}$ & $0.92^{\mathrm{b}} \pm 0.04$ & $0.95^{\mathrm{b}} \pm 0.08$ & $0.66^{\mathrm{a}} \pm 0.04$ & $<0.22$ & 0.21 & 0.52 & 2.77 & - \\
\hline
\end{tabular}

${ }^{*}$ Means ( \pm standard errors) with the same letter within rows did not differ significantly according to the Student-Newman-Keuls test at $p<0.05$.

Nigella oil [27] but less stable than argan oil [25], sesame oil [26], and extra virgin olive oil [23, 24]. This difference in stability between oils is marked for the secondary oxidation reactions evaluated by $\mathrm{K}_{270}$. Several factors may be involved in this difference, notably fatty acid content and the presence of antioxidant molecules, such as phenols and tocopherols [30].

\subsection{Chemical Composition}

3.3.1. Pigment Content. The evaluation of the pigment content in the obtained oils revealed higher contents of $\alpha$-pheophytin and carotenoids than those of chlorophyll. They vary from 3.69 to $5.23 \mathrm{ppm}$ for $\alpha$-pheophytin, 3.55 to $3.68 \mathrm{ppm}$ for carotenoids, and 0.93 to $3.33 \mathrm{ppm}$ for chlorophyll (Figure 1). A highly significant difference in $\alpha$-pheophytin and chlorophyll pigments content was noted between the three varieties. Oil from the "Aakria" variety was distinguished by the highest contents of the two pigments (5.23 and $3.33 \mathrm{ppm}$, respectively) giving this oil a greener hue. However, no significant difference was observed between the carotenoid content among the tested varieties.

The carotenoid contents recorded for the oils of the three varieties ensured their stability and resistance to oxidation during storage. Chlorophyll, although interesting in terms of its antioxidant activity, has prooxidant effects in the light unlike carotenoids, which have a protective effect against photooxidation by deactivating the oxygen singlet [18].

3.3.2. Fatty Acid Composition. The seed oils of the two species OFI and OM represented by "Safra," "Aakria," and "Derbana" varieties are composed mainly of unsaturated fatty acids (USFAs) $(82.77 \%-82.99 \%)$, with the following two forms: monounsaturated and polyunsaturated fatty acids (Table 2). Saturated fatty acids (SFAs) have been detected at low rates of approximately $17 \%$. The USFA/SFA ratio did not differ significantly between the studied varieties (4.80-4.88). Linoleic acid was the major fatty acid (60.55\%$63.46 \%)$, followed by oleic acid $(18.8 \%-21.81 \%)$ and palmitic acid (13.75\%-13.75\%). The two OFI varieties ("Aakria” and "Safra") showed higher levels of linoleic and palmitic acids than the OM variety. The latter variety, however, revealed

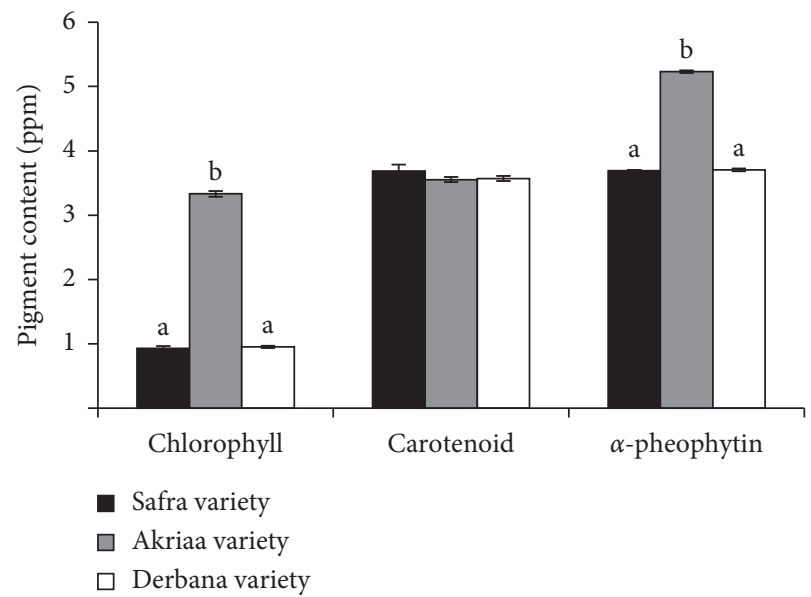

FIGURE 1: Chlorophyll, carotenoid, and $\alpha$-pheophytin contents of seed oils of two prickly pear species: Opuntia ficus-indica "Safra" and "Aakria" varieties) and Opuntia megacantha ("Derbana" variety). Means with the same letter for the same pigment did not differ significantly according to the Student-Newman-Keuls test at $p<0.05$. Error bars represent the standard error of three replicates.

significantly high levels of oleic and stearic acids $(21.82 \%$ and $3.30 \%$, respectively). Furthermore, the C18:2/C18:1 ratios of the two varieties of OFI species were significantly higher than those of other OM species. Thus, the highly significant differences in fatty acids mentioned above may be useful markers for differentiating between the oils of the two species, OFI and OM, because the impacts of environmental and agronomic factors (e.g., geographical origin, fruit ripening stage, and harvest period) are ruled out.

The contents of the major fatty acids of the studied species are in agreement with those found in previous studies on OFI species [9, 29]. Nonetheless, other studies have reported higher levels of palmitic acid (exceeding 16\%) and linoleic acid (70\%) [10]. The difference in the linoleic acid content found in some studies could be due to the fruit genotype or maturity stage.

The comparison of fatty acid profiles of the studied prickly pear oils with those of oils from other vegetable species revealed a higher content of linoleic acid in the prickly pear seed oil $(60.55 \%-63.46 \%)$ than those of sesame oil (42.10\%) [26] and Nigella oil (56.50\%) [27] and a much 
TABLE 2: Fatty acid composition of seed oils of two species of prickly pear: Opuntia ficus-indica ("Safra" and "Aakria" varieties) and Opuntia megacantha ("Derbana" variety) compared with other nutraceutical and cosmetic oils*.

\begin{tabular}{|c|c|c|c|c|c|c|c|c|}
\hline \multirow{3}{*}{ Fatty acids (\%) } & \multicolumn{3}{|c|}{ Prickly pear species and varieties } & \multicolumn{5}{|c|}{ Nutraceutical and cosmetic fruit and seed oils } \\
\hline & \multicolumn{2}{|c|}{ Opuntia ficus-indica } & \multirow{2}{*}{$\begin{array}{c}\text { Opuntia } \\
\text { megacantha } \\
\text { Derbana }\end{array}$} & \multirow{2}{*}{$\begin{array}{c}\text { Olive, Olea } \\
\text { europaea } \\
{[24,31]}\end{array}$} & \multirow{2}{*}{$\begin{array}{c}\text { Argan, } \\
\text { Argania } \\
\text { spinosa }[25]\end{array}$} & \multirow{2}{*}{$\begin{array}{c}\text { Sesame, } \\
\text { Sesamum } \\
\text { indicum }[26]\end{array}$} & \multirow{2}{*}{$\begin{array}{c}\text { Black } \\
\text { cumin, } \\
\text { Nigella } \\
\text { sativa [27] }\end{array}$} & \multirow{2}{*}{$\begin{array}{c}\text { Lentisk, } \\
\text { Pistacia } \\
\text { lentiscus }\end{array}$} \\
\hline & Safra & Aakria & & & & & & \\
\hline $\begin{array}{l}\text { Myristic acid } \\
(\mathrm{C} 14: 0)\end{array}$ & $0.10^{\mathrm{a}} \pm 0.00$ & $0.11^{\mathrm{a}} \pm 0.00$ & $0.13^{\mathrm{b}} \pm 0.00$ & - & - & 0.10 & 0.20 & - \\
\hline $\begin{array}{l}\text { Pentadecylic acid } \\
(\mathrm{C} 15: 0)\end{array}$ & $0.05^{\mathrm{a}} \pm 0.01$ & $0.06^{\mathrm{a}} \pm 0.00$ & $0.21^{b} \pm 0.05$ & - & - & - & - & - \\
\hline $\begin{array}{l}\text { Palmitic acid } \\
(\mathrm{C} 16: 0)\end{array}$ & $13.64^{\mathrm{b}} \pm 0.06$ & $13.75^{\mathrm{b}} \pm 0.11$ & $13.03^{\mathrm{a}} \pm 0.15$ & $7.50-20.00$ & $11.5-15$ & 11.30 & 11.90 & $20.51-23.01$ \\
\hline $\begin{array}{l}\text { Palmitoleic acid } \\
(\mathrm{C} 16: 1)\end{array}$ & $0.06^{\mathrm{a}} \pm 0.00$ & $0.06^{\mathrm{a}} \pm 0.00$ & $0.06^{\mathrm{a}} \pm 0.00$ & $0.30-3.50$ & 0.1 & - & 0.20 & $0.38-0.53$ \\
\hline $\begin{array}{l}\text { Margaric acid } \\
(\mathrm{C} 17: 0)\end{array}$ & $0.04^{\mathrm{a}} \pm 0.00$ & $0.04^{\mathrm{a}} \pm 0.00$ & $0.02^{\mathrm{a}} \pm 0.01$ & - & - & - & - & - \\
\hline $\begin{array}{l}\text { Heptadecenoic } \\
\text { acid }(\mathrm{C} 17: 1)\end{array}$ & $0.04^{\mathrm{a}} \pm 0.01$ & $0.04^{\mathrm{a}} \pm 0.00$ & $0.03^{\mathrm{a}} \pm 0.02$ & $<0.30$ & - & - & - & - \\
\hline $\begin{array}{l}\text { Stearic acid } \\
(\mathrm{C} 18: 0)\end{array}$ & $2.97^{\mathrm{a}} \pm 0.02$ & $2.99^{\mathrm{a}} \pm 0.01$ & $3.30^{\mathrm{b}} \pm 0.00$ & $0.50-5.00$ & $3.4-7.4$ & 4.9 & 3.20 & $0.98-1.30$ \\
\hline $\begin{array}{l}\text { Oleic acid (C18: } \\
\text { 1n9) }\end{array}$ & $14.22^{\mathrm{a}} \pm 0.08$ & $14.09^{\mathrm{a}} \pm 0.04$ & $17.40^{\mathrm{b}} \pm 0.01$ & - & - & - & - & - \\
\hline $\begin{array}{l}\text { Oleic acid (C18: } \\
\ln 7)\end{array}$ & $4.66^{\mathrm{b}} \pm 0.03$ & $4.67^{\mathrm{b}} \pm 0.02$ & $4.42^{\mathrm{a}} \pm 0.01$ & - & - & - & - & - \\
\hline $\begin{array}{l}\text { Oleic acid (C18: } \\
\text { 1) }\end{array}$ & $18.88^{\mathrm{a}} \pm 0.07$ & $18.75^{\mathrm{a}} \pm 0.03$ & $21.81^{b} \pm 0.02$ & $55.00-83.00$ & $43.3-49.1$ & 41.90 & 24.90 & $51.56-53.23$ \\
\hline $\begin{array}{l}\text { Linoleic acid } \\
(\mathrm{C} 18: 2)\end{array}$ & $63.46^{\mathrm{b}} \pm 0.12$ & $63.45^{\mathrm{b}} \pm 0.06$ & $60.55^{\mathrm{a}} \pm 0.13$ & $2.50-21.00$ & $28-36$ & 42.10 & 56.50 & $20.95-23.77$ \\
\hline $\begin{array}{l}\text { Linolenic acid } \\
(\mathrm{C} 18: 3)\end{array}$ & $0.24^{\mathrm{a}} \pm 0.00$ & $0.25^{\mathrm{a}} \pm 0.02$ & $0.30^{\mathrm{a}} \pm 0.03$ & $<1.00$ & $<0.40$ & 0.20 & 0.20 & $1.31-1.54$ \\
\hline $\begin{array}{l}\text { Arachidic acid } \\
(\mathrm{C} 20: 0)\end{array}$ & $0.28^{\mathrm{a}} \pm 0.00$ & $0.29^{\mathrm{a}} \pm 0.02$ & $0.31^{\mathrm{a}} \pm 0.01$ & $<0.50$ & $0.30-0.50$ & - & 0.20 & - \\
\hline $\begin{array}{l}\text { Gadoleic acid } \\
(\mathrm{C} 20: 1)\end{array}$ & $0.24^{\mathrm{a}} \pm 0.00$ & $0.21^{\mathrm{a}} \pm 0.01$ & $0.23^{\mathrm{a}} \pm 0.01$ & $<0.40$ & $0.40-0.30$ & - & - & - \\
\hline $\begin{array}{l}\text { Ratio (C18:2/ } \\
\text { C18:1) }\end{array}$ & $3.36^{\mathrm{b}} \pm 0.00$ & $3.38^{\mathrm{b}} \pm 0.00$ & $2.78^{\mathrm{a}} \pm 0.00$ & $4.71-20.33$ & $1.36-1.54$ & 1.00 & 0.44 & $2.07-2.40$ \\
\hline $\begin{array}{l}\text { Saturated fatty } \\
\text { acids (SFA) }\end{array}$ & $17.08^{\mathrm{a}} \pm 0.09$ & $17.23^{\mathrm{b}} \pm 0.16$ & $17.01^{\mathrm{a}} \pm 0.31$ & $13-22$ & $14-24$ & 16.30 & 15.50 & $22.25-24.50$ \\
\hline $\begin{array}{l}\text { Unsaturated fatty } \\
\text { acids (USFA) }\end{array}$ & $82.92^{\mathrm{a}} \pm 0.09$ & $82.77^{\mathrm{a}} \pm 0.15$ & $82.99^{\mathrm{a}} \pm 0.30$ & $66-96$ & $71-88$ & 84.30 & 82.10 & - \\
\hline USFA/SFA & $4.85^{\mathrm{a}} \pm 0.03$ & $4.80^{\mathrm{a}} \pm 0.05$ & $4.88^{\mathrm{a}} \pm 0.06$ & $3.13-5.07$ & $3.66-5.07$ & 5.20 & 5.30 & $3.13-3.45$ \\
\hline Iodine value (IV) & $132.81^{\mathrm{b}} \pm 0.15$ & $132.73^{\mathrm{b}} \pm 0.11$ & $130.34^{\mathrm{a}} \pm 0.35$ & $77.50-88.56$ & $89.6-110.4$ & 114.60 & 126.2 & - \\
\hline
\end{tabular}

${ }^{*}$ Means ( \pm standard errors) with the same letter within rows did not differ significantly according to the Student-Newman-Keuls test at $p<0.05$.

higher content than that of olive oil (3\%-14\%) [24], argan oil $(28 \%-36 \%)$ [25], and lentisk oil (20.95\%-23.77\%) [28] (Table 2). The oleic acid/linoleic acid ratio of the prickly pear seed oil varied from 0.30 to 0.36 , unlike olive, argan, and lentisk oils, for which the oleic acid content is higher than that of linoleic acid with an oleic acid/linoleic acid ratio varying from 4.71 to 20.33 for olive oil [24, 31], 1.36 to 1.54 for argan oil [25], and 2.24 to 2.46 for lentisk oil [28].

IV is primarily used to describe oil unsaturation and may also be used to determine the oxidative stability of an oil. A low IV value indicates that the stability of oil is high. The results obtained in this study show that OM oil ("Derbana" variety) is relatively more stable with an IV of 130.34 compared to respective values of 132.81 and 132.73 for the oils of the two OFI varieties ("Safra" and "Aakria") (Table 2). This result is in agreement with that of the specific extinction. This interspecific difference in stability can be explained by the difference in the proportions of oleic acid, which, according to some authors, directly impacts the stability of the oil [32]. Consequently, the oil from prickly pear seeds is susceptible to various oxidative processes and exhibits high instability compared to argan oil [33].

The high proportions of USFAs detected in the studied oils are of great interest due to their nutritional and pharmaceutical potential. The literature clearly illustrates their role in the prevention of cardiovascular diseases, atherosclerosis, autoimmune disorders, and diabetes [34]. Linoleic acid has also shown various cosmetic properties, in particular its effect on skin dryness and flaking [35]. Thus, these oils can constitute an interesting resource for the formulation of dermatological and cosmetic products. 
3.3.3. Triglyceride Composition. The triglyceride composition of the seed oils derived from the studied prickly pear varieties is presented in Table 3 . The predominant component is LLL (24.33\%-26.49\%), followed by OLL (20.92\%$21.92 \%$ ) and three fractions dioleoyl-linolenoyl-glycerol and palmitoyl-dioleoyl-linoleoyl-glycerol (OOLn + PoOL) (16.45\%-18.84\%), palmitoyl-oleoyl-linoleoyl-glycerol and stearoyl-dilinoleoyl-glycerol and palmitoyl-dioleoyl-glycerol $(\mathrm{POL}+\mathrm{SLL}+\mathrm{PoOO})(13.26 \%-13.43 \%)$, and oleoyl-dilinoleoyl-glycerol and dipalmitoyl-linolenoyl-glycerol and palmitoyl-dioleoyl-glycerol (OOL +

$\mathrm{PLnP}+\mathrm{PoOO})(7.66 \%-9.27 \%)$. PPL, triolein (OOO), and dipalmitoyl-oleoyl-glycerol (POP) are minor compounds whose respective contents do not exceed $4 \%$. Other triglycerides are found in traces such as gadoyl-dioleoylglycerol ( $\mathrm{GaOO})$, SOO, palmitoyl-oleoyl-stearoyl-glycerol (POS), and AOO.

The comparison of triglyceride composition between oils of the three varieties revealed highly significant differences in LLL, OOLn + PoOL, OOL + PLnP + PoOO, POO + SOL (palmitoyl-dioleoyl-glycerol and stearoyl-oleoyl-linoleoylglycerol fraction), and OOO contents. . The "Aakria" variety of OFI species was found to have the highest contents of LLL and OOLn + PoOL (26.49\% and 18.84\%, respectively), and the Derbana "variety" was found to have the highest contents of $\mathrm{OOL}+\mathrm{PLnP}+\mathrm{PoOO}, \mathrm{POO}+\mathrm{SOL}$, and $\mathrm{OOO}(9.27 \%$, $5.06 \%$, and $2.32 \%$, respectively). Other triglyceride contents exhibited significant differences among the three varieties, especially OLL, PPL, OLLn + PoLL, and SOO. Hence, these could be considered species markers because these variations were observed despite both species having been cultivated under the same soil, climatic, ripening, and harvest conditions. In addition, the OFI triglyceride profile obtained in this study by solvent extraction differs from that described by Zine et al. [25] for cold press oil extraction from OFI (LLL and OLL contents of $24.94 \%$ and $21.3 \%$, respectively). Thus, the extraction method is expected to affect triglyceride levels. Conversely, the data found in this study are close to those of OFI seed oil from Tunisia extracted using solvent. The main triglycerides were LLL (25.60\%), OLL (21.53\%), and POL + SLL (12.73\%) [36].

The comparison of triglyceride composition of the seed oils extracted from OFI and OM species with other vegetable oils reveals a similar composition with that of walnut oil, in which the major triglycerides are LLL (23.7\%) and OLL (19.7\%) [37]. In contrast, a clear difference between the obtained oils with olive and argan oils was observed, which was clearly indicated by the dominance of OOO, whose content can reach $58.34 \%$ for olive oil [38] and $13.21 \%$ for argan oil [25]. A significant difference was also observed with lentisk oil, in which the main triglyceride was POO + SOL (varying between $21.24 \%$ and $24.71 \%$ ) [28].
TABLE 3: Triglyceride composition of seed oils of two prickly pear species: Opuntia ficus-indica ("Safra" and "Aakria" varieties) and Opuntia megacantha ("Derbana" variety).

\begin{tabular}{|c|c|c|c|}
\hline \multirow{3}{*}{ Triglycerides* (\%) } & \multicolumn{3}{|c|}{ Prickly pear species and varieties** } \\
\hline & \multicolumn{2}{|c|}{ Opuntia ficus-indica } & \multirow{2}{*}{$\begin{array}{c}\text { Opuntia } \\
\text { megacantha } \\
\text { Derbana }\end{array}$} \\
\hline & Safra & Aakria & \\
\hline LLL & $25.53^{\mathrm{b}} \pm 0.02$ & $26.49^{c} \pm 0.05$ & $24.33^{\mathrm{a}} \pm 0.04$ \\
\hline OLLn + & $0.18^{\mathrm{a}} \pm 0.00$ & $0.17^{\mathrm{a}} \pm 0.00$ & $0.20^{\mathrm{b}} \pm 0.00$ \\
\hline PLLn & $0.17^{\mathrm{a}} \pm 0.00$ & $0.16^{\mathrm{a}} \pm 0.00$ & $0.16^{\mathrm{a}} \pm 0.00$ \\
\hline OLL & $20.92^{\mathrm{a}} \pm 0.04$ & $20.96^{\mathrm{a}} \pm 0.02$ & $21.92^{\mathrm{b}} \pm 0.05$ \\
\hline $\mathrm{OOLn}+\mathrm{PoOL}$ & $18.54^{\mathrm{b}} \pm 0.06$ & $18.84^{\mathrm{c}} \pm 0.02$ & $16.45^{\mathrm{a}} \pm 0.03$ \\
\hline POLn & $0.11^{\mathrm{a}} \pm 0.02$ & $0.10^{\mathrm{a}} \pm 0.00$ & $0.11^{\mathrm{a}} \pm 0.00$ \\
\hline$+\mathrm{PLnP}+\mathrm{PoOO}$ & $8.02^{\mathrm{b}} \pm 0.02$ & $7.66^{\mathrm{a}} \pm 0.02$ & $9.27^{\mathrm{c}} \pm 0.02$ \\
\hline $\mathrm{POL}+\mathrm{SLL}+\mathrm{PoOO}$ & $13.43^{\mathrm{b}} \pm 0.01$ & $13.29^{\mathrm{a}} \pm 0.01$ & $13.26^{\mathrm{a}} \pm 0.01$ \\
\hline PPL & $3.11^{\mathrm{b}} \pm 0.03$ & $3.03^{\mathrm{b}} \pm 0.01$ & $2.54^{\mathrm{a}} \pm 0.00$ \\
\hline $\mathrm{OOO}$ & $1.39^{\mathrm{b}} \pm 0.08$ & $1.14^{\mathrm{a}} \pm 0.04$ & $2.32^{\mathrm{c}} \pm 0.00$ \\
\hline $\mathrm{POO}+\mathrm{SOL}$ & $4.57^{\mathrm{b}} \pm 0.08$ & $4.24^{\mathrm{a}} \pm 0.01$ & $5.06^{c} \pm 0.00$ \\
\hline POP & $2.92^{\mathrm{b}} \pm 0.07$ & $2.63^{\mathrm{a}} \pm 0.00$ & $2.70^{\mathrm{a}} \pm 0.03$ \\
\hline $\mathrm{GaOO}$ & $0.38^{\mathrm{a}} \pm 0.03$ & $0.32^{\mathrm{a}} \pm 0.00$ & $0.34^{\mathrm{a}} \pm 0.00$ \\
\hline SOO & $0.39^{a} \pm 0.03$ & $0.38^{\mathrm{a}} \pm 0.01$ & $0.51^{\mathrm{b}} \pm 0.00$ \\
\hline POS & $0.34^{\mathrm{a}} \pm 0.05$ & $0.44^{\mathrm{b}} \pm 0.00$ & $0.59^{\mathrm{c}} \pm 0.01$ \\
\hline $\mathrm{AOO}$ & $0.13^{\mathrm{a}} \pm 0.00$ & $0.13^{\mathrm{a}} \pm 0.00$ & $0.13^{\mathrm{a}} \pm 0.02$ \\
\hline SOS & $0.01^{\mathrm{a}} \pm 0.01$ & $0.01^{\mathrm{a}} \pm 0.00$ & $0.00^{\mathrm{a}} \pm 0.00$ \\
\hline
\end{tabular}

${ }^{*}$ P, palmitoyl radical; Po, palmitoleyl radical; O, oleoyl radical; L, linoleoyl radical; Ln, linolenoyl radical; S, stearoyl radical; Ga, gadoleyl radical. ${ }^{* *}$ Means ( \pm standard errors) with the same letter within lines did not differ significantly according to the Student-Newman-Keuls test at $p<0.05$.

\section{Conclusions}

Significant differences in the physical quality parameters and chemical composition of seed oils extracted from "Safra," "Aakria," and "Derbana" varieties belonging to OFI and OM species of prickly pear were identified in this study. Key differences were noted between OM oil ("Derbana" variety) and OFI oils ("Safra" and "Aakria" varieties) in terms of oil stability parameters $\left(\mathrm{K}_{232}\right.$ and $\left.\mathrm{K}_{270}\right)$, fatty acid content, and triglyceride composition. The three studied oils mainly contained linoleic acid, an essential fatty acid with a content exceeding 60\%; the highest linoleic acid content was recorded for the OFI species. The oil extracted from OM ("Derbana") was characterized by significantly lower linoleic and palmitic acid contents and higher oleic and stearic acid contents. In addition, some triglycerides could be considered as markers of differentiation between the two species, especially OLL, PPL, OLLn + PoLL, and SOO. High proportions of USFAs and the high linoleic acid contents detected in the studied oils stimulated great interest because of their potential in nutritional and pharmaceutical applications. Thus, this study confirmed that these oils may be an interesting resource for developing a range of skin products, highlighting the importance of prickly pear seed oil as a 
potential alternative to existing commercial cosmetic oils. Additionally, this preliminary investigation revealed that OM oil may be highly stable. Therefore, extensive studies on oxidative stability and shelf life are necessary to further elucidate the characteristics of OM prickly pear seed oils.

\section{Data Availability}

The data used to support the findings of this study are available from the first author Fatima Ettalibi (fa.ettalibi@ gmail.com) upon request.

\section{Disclosure}

This research was performed at the Regional Center for Agricultural Research in Marrakesh belonging to the $\mathrm{Na}$ tional Institute for Agricultural Research (INRA Morocco) in the framework of the Megaproject: "Preservation and development of the cactus sector" of INRA Medium-Term Research Program (PRMT).

\section{Conflicts of Interest}

The authors declare that there are no conflicts of interest.

\section{Acknowledgments}

The authors are grateful to the Sebbar Rhamna Cooperative and to farmers of the rural commune of Sidi Abdellah (Skhour Rhamna, Morocco) for their substantial assistance during prickly pear fruit harvesting. They would also like to extend their thanks to the technical staff of the Agro-Food Technology and Quality Laboratory at the Regional Center of Agricultural Research of Marrakesh (INRA Morocco) for providing technical support during the development of this research.

\section{References}

[1] M. Arba, "Le cactus Opuntia, une espèce fruitière et fourragère pour une agriculture durable au Maroc," in Proceedings of the Actes du Symposium International-Durabilité des systèmes de culture en zone méditerranéenne et gestion des ressources en eau et en sol (AGDUMED), pp. 215-223, Rabat, Morocco, 2009.

[2] M. Boujghagh, Le Guide pratique de conduite technique de la culture:Le cactus (Opuntia spp.), INRA, Rabat, Morocco, 2011.

[3] C. S. C. Bencke and L. P. C. Morellato, "Comparação de dois métodos de avaliação da fenologia de plantas, sua interpretação e representação," Revista Brasileira de Botânica, vol. 25, no. 3, pp. 269-275, 2002.

[4] M. Y. Elhadi and M. J. Candelario, "Nutritional components and anti-oxidant capacity of ten cultivars and lines of cactus pear fruit (Opuntia spp.)," Food Research International, vol. 44, no. 7, pp. 2311-2318, 2011.

[5] J. A. Fernández-López and L. Almela, "Application of highperformance liquid chromatography to the characterization of the betalain pigments in prickly pear fruits," Journal of Chromatography A, vol. 913, no. 1-2, pp. 415-420, 2001.

[6] F. Ettalibi, H. Elmahdaoui, J. Amzil, C. Gadhi, and H. Harrak, "Drying impact on physicochemical and biochemical criteria of prickly pear fruit peels of three varieties of Opuntia spp." Materials Today: Proceedings, vol. 27, pp. 3243-3248, 2020.

[7] A. Homrani Bakali, H. Harrak, and Y. Noutfia, "Étude de la variabilité phénotypique du fruit de figuier de Barbarie d'une collection ex-situ d'accessions locales dans le contexte oasien du Tafilalet-Maroc," African and Mediterranean Agricultural Research Journal - AlAwamia, vol. 131, pp. 91-116, 2021.

[8] M. M. Özcan and F. Y. Al Juhaimi, "Nutritive value and chemical composition of prickly pear seeds (Opuntia ficus indica L.) growing in Turkey," International Journal of Food Sciences and Nutrition, vol. 62, no. 5, pp. 533-536, 2011.

[9] M. F. Ramadan and J.-T. Mörsel, "Oil cactus pear (Opuntia ficus-indica L.)," Food Chemistry, vol. 82, no. 3, pp. 339-345, 2003.

[10] M. Ennouri, B. Evelyne, M. Laurence, and A. Hamadi, "Fatty acid composition and rheological behaviour of prickly pear seed oils,” Food Chemistry, vol. 93, no. 3, pp. 431-437, 2005.

[11] F. Taoufik, S. Zine, M. El Hadek et al., "Oil content and main constituents of cactus seed oils Opuntia ficus indica of different origin in Morocco," Mediterranean Journal of Nutrition and Metabolism, vol. 8, no. 2, pp. 85-92, 2015.

[12] V. K. Karabagias, I. K. Karabagias, I. Gatzias, and A. V. Badeka, "Prickly pear seed oil by shelf-grown cactus fruits: waste or maste?" Processes, vol. 8, no. 132, 11 pages, 2020.

[13] B. Matthäus and M. M. Özcan, "Habitat effects on yield, fatty acid composition and tocopherol contents of prickly pear (Opuntia ficus-indica L.) seed oils," Scientia Horticulturae, vol. 131, no. 1, pp. 95-98, 2012.

[14] F. Ettalibi, A. El Antari, C. Gadhi, and H. Harrak, "Oxidative stability at different storage conditions and adulteration detection of prickly pear seeds oil," Journal of Food Quality, vol. 2020, Article ID 8837090, 12 pages, 2020.

[15] IOC, Spectrophotometric Analysis in Ultraviolet, International Olive Council, Madrid, Spain, 2010.

[16] AFNOR, Recueil de Normes Françaises des Corps Gras, Graines Oléagineuses, Produits Dérivés, Association Française de Normalisation, Paris, 3nd edition, 1984.

[17] J. P. Wolff, Manuel d'analyse Des Corps Gras, Vol. 517, Azoulay, Paris, 1968.

[18] E. Psomiadou and M. Tsimidou, "Pigments in Greek virgin olive oils: occurrence and levels," Journal of the Science of Food and Agriculture, vol. 81, no. 7, pp. 640-647, 2001.

[19] M. I. Mosquera-Minguez, L. Rejano, B. Guandul, A. H. Sanchez, and J. Garido, "Color pigment, correlation in virgin olive oil," Journal of the American Oil Chemists' Society, vol. 68, no. 5, pp. 332-336, 1991.

[20] IOC, Determination of Fatty Acid Methyl Esters by Gas Chromatography, International Olive Council, Madrid, Spain, 2017.

[21] H. Diraman and H. Dibeklioğlu, "Characterization of Turkish virgin olive oils produced from early harvest olives," Journal of the American Oil Chemists' Society, vol. 86, no. 7, pp. 663-674, 2009.

[22] European Union Commission, "Regulation EEC 2568/91 on the characteristics of olive oil and olive-residue oil and on the relevant methods of analysis," Official Journal of European Communities, vol. 248, pp. 1-81, 1991.

[23] B. Aganchich, A. El Antari, S. Wahbi, H. Tahi, R. Wakrim, and R. Serraj, "Fruit and oil quality of mature olive trees under partial root zone drying in field conditions," Grasas y Aceites, vol. 59, pp. 225-233, 2008. 
[24] IOC, Applicable Commercial Standard with Olive Oils and Olive Pomace Oils, International Olive Council, Madrid, Spain, 2019.

[25] S. Zine, S. Gharby, and M. El Hadek, "Physicochemical characterization of Opuntia ficus-indica seed oil from Morocco," Biosciences Biotechnology Research Asia, vol. 10, no. 1, pp. 1-7, 2013.

[26] S. Gharby, H. Harhar, Z. Bouzoubaa, A. Asdadi, A. El Yadini, and Z. Charrouf, "Chemical characterization and oxidative stability of seeds and oil of sesame grown in Morocco," Journal of the Saudi Society of Agricultural Sciences, vol. 16, no. 2, pp. 105-111, 2017.

[27] S. Gharby, H. Harhar, D. Guillaume et al., "Chemical investigation of Nigella sativa L. seed oil produced in Morocco," Journal of the Saudi Society of Agricultural Sciences, vol. 14, no. 2, pp. 172-177, 2015.

[28] B. Ait Mohand, A. El Antari, and F. Benkhalti, "Chemical composition of Pistacia lentiscus seeds' oil from Moroccan high atlas mountain," Journal of Food Quality, vol. 2020, Article ID 5190491, 5 pages, 2020.

[29] N. Chougui, A. Tamendjari, W. Hamidj et al., "Oil composition and characterization of phenolic compounds contents of Opuntia ficus indica seeds," Food Chemistry, vol. 139, no. 1-4, pp. 796-803, 2013.

[30] J. Rodrigues, I. Miranda, J. Gominho et al., "Variability in oil content and composition and storage stability of seeds from Jatropha curcas L. grown in Mozambique," Industrial Crops and Products, vol. 50, pp. 828-837, 2013.

[31] N. Boukachabine, H. Ajana, and A. El Antari, "A study of fatty acids and triglycerides oil composition and quality parameters of five autochthon olive varieties in Morocco," Lebanese Science Journal, vol. 12, no. 2, pp. 45-65, 2011.

[32] S. S. H. Allam, "Utilization of some untraditional sources of high oleic acid oils for improving vegetable oils stability," Rivista Italiana Delle Sostanze Grasse, vol. 78, no. 6, pp. 337-341, 2001.

[33] S. Gharby, D. Guillaume, I. Nounah et al., "Shelf-life of Moroccan prickly pear (Opuntia ficus-indica) and argan (Argania spinosa) oils: a comparative study," Grasas y Aceites, vol. 72, no. 1, p. e397, 2021.

[34] F. B. Hu, "Plant-based foods and prevention of cardiovascular disease: an overview," American Journal of Clinical Nutrition, vol. 78, no. 3, pp. 544S-551S, 2003.

[35] R. T. Holman, "The slow discovery of the importance of $\omega 3$ essential fatty acids in human health," Journal of Nutrition, vol. 128, no. 2, pp. 427S-433S, 1998.

[36] I. El Mannoubi, S. Barrek, T. Skanji, H. Casabianca, and H. Zarrouk, "Characterization of Opuntia ficus indica seed oil from Tunisia," Chemistry of Natural Compounds, vol. 45, no. 5, pp. 616-620, 2009.

[37] R. Oliveria, M. F. Rodriques, and M. G. Bernardo-Gil, "Characterization and supercritical carbon dioxide extraction of walnut oil," Journal of the American Oil Chemists' Society, vol. 79, no. 3, pp. 252-230, 2002.

[38] K. Tanouti, H. Serghini-Caid, E. Chaieb, A. Benali, M. Harkous, and A. Elamrani, "Amélioration qualitative d'huiles d'olive produites dans le Maroc Oriental," Les Technologies De Laboratoire, vol. 6, no. 22, pp. 1-13, 2011. 